\title{
SALA DE RECURSOS MULTIFUNCIONAL: O ENSINO DE CIÊNCIAS NUMA PERSPECTIVA INCLUSIVA
}

\section{MULTIFUNCTIONAL RESOURCE CLASSROOM: TEACHING SCIENCE IN AN INCLUSIVE PERSPECTIVE}

\author{
Rejane Fernandes da Silva Vier \\ Universidade Tecnológica Federal do Paraná - UTFPR Câmpus Ponta Grossa/ PPGECT / \\ rejanevier@hotmail.com

\section{Rosemari Monteiro Castilho Foggiatto Silveira} \\ Universidade Tecnológica Federal do Paraná - UTFPR Câmpus Ponta Grossa/ PPGECT/ \\ foggiattorm@hotmail.com
}

\section{Resumo}

Este artigo discute o papel das Salas de Recursos Multifuncionais (SRM) no ensino de ciências para alunos público-alvo da educação especial, na percepção dos professores, tendo por objetivo promover uma reflexão sobre a inclusão educacional, por meio do ensino de Ciências, bem como identificar os avanços e os retrocessos no trabalho desenvolvido pelos professores na prática educacional inclusiva. A abordagem metodológica foi qualitativa de cunho exploratório. Para a coleta de dados, foi realizada uma entrevista com os professores que atuam na classe comum do ensino regular com a disciplina de Ciências, nas séries finais do Ensino Fundamental, professores da SRM e equipe pedagógica, em uma escola da rede estadual de ensino do município de Ponta Grossa, Paraná, que oferta o programa de atendimento educacional especializado. Os resultados obtidos nesse estudo ressaltam a possibilidade de promover a inclusão educacional por meio do ensino de Ciências, tendo em vista a proximidade dos conteúdos com o cotidiano dos alunos. Entretanto, destaca-se a importância da proposta numa perspectiva coletiva e participativa, que promova de fato a Inclusão Educacional no ambiente escolar.

Palavras-chave: Ensino de Ciências, Salas de Recursos Multifuncionais, Inclusão Educacional.

\section{Abstract}

This scientific article discusses the role of the Multifunctional Resource Classrooms (MRC) in Science education for public-targeted students of special education, into the teachers' perception, having the goal of promoting a reflection on educational inclusion through science teaching, as well as identifying advances and setbacks in teachers' work on inclusive educational practice. The methodological approach was qualitative and exploratory. For data collection, an interview was conducted with the teachers who work in 
regular education Science classes for the final years of Elementary School, MRC teachers and the pedagogical team in a state school in the municipality of Ponta Grossa, in the state of Parana, which offers a specialized educational service program. The results from this study could highlight the possibility of promoting educational inclusion through Science teaching, due to the close relationship between the contents and the students' daily lives. However, the importance of a collective and participatory perspective must be highlighted to promote actual Educational Inclusion in the school environment.

Keywords: Science teaching, Multifunctional Resource Classroom (MRC), Educational Inclusion.

\section{Introdução}

A cada dia, a inclusão educacional deixa de se caracterizar apenas como um discurso histórico, teórico, político e legal no Brasil, constituindo-se como uma realidade nas escolas. No entanto, essa realidade ainda traz consigo um grande desafio ao coletivo escolar. Os educadores assumem a tarefa de promover a inclusão de alunos com deficiência que são os alunos público-alvo da educação especial, em um sistema de ensino que ainda apresenta características tradicionais, excludentes e que, na maioria das vezes preconiza aspectos como a transmissão de conteúdos a serem acumulados e mensurados por meio de uma avaliação meramente valorativa e classificatória que não condiz com a proposta de adaptação curricular para a promoção da inclusão educacional.

Os alunos atendidos pelo programa de atendimento educacional especializado de $\mathrm{SRM}$, nas séries finais do ensino fundamental da rede estadual de ensino, conforme as orientações da Deliberação 02/03, são alunos com diagnóstico clínico de deficiência intelectual e transtornos funcionais específicos, que passam por avaliação pedagógica no contexto escolar, realizada em conjunto pelo professor especialista em educação especial, equipe pedagógica e pelos professores da classe comum do ensino regular. (PARANÁ, 2003)

O programa tem por objetivo complementar e suplementar o trabalho desenvolvido em sala de aula. Nessa perspectiva, entende-se que a inclusão do aluno deve partir da sala de aula, do ensino regular, sendo um exercício para o coletivo da escola, tarefa essa que não se restringe ao professor especialista e ao espaço da SRM, mas sim ao coletivo escolar. Sendo assim, por meio de um trabalho integrado e participativo, o programa poderá possibilitar a organização da prática pedagógica dos professores para que esses possam, também, na classe comum, promover a inclusão dos alunos e a participação no processo de ensino e aprendizagem.

A SRM é um programa no qual o aluno recebe atendimento de um professor especialista em período contrário ao ensino regular, no entanto, a tarefa do professor especialista não se restringe ao atendimento específico ao aluno, mas também aos professores e familiares, de modo a favorecer o processo de inclusão desse aluno na classe comum do ensino regular, dando subsídios para que os professores também possam adotar práticas pedagógicas inclusivas. 
Há uma preocupação muito grande no meio escolar com a transmissão de conceitos considerados fundamentais na formação do sujeito. No ensino de ciências, essa preocupação se divide entre os conceitos a serem assimilados e a formação do cidadão para tomada de decisões em relação às questões científicas e tecnológicas. Nessa perspectiva, é possível identificar a possibilidade de promover a inclusão por meio do ensino de ciências em que o educando, independente de suas condições, possa participar ativamente de sua aprendizagem e das decisões de um coletivo.

A tarefa de avaliar os possíveis resultados, as dificuldades enfrentadas e o caminho percorrido para que a inclusão realmente se efetive, não é uma tarefa fácil e envolve todos os profissionais que fazem parte desse processo, para que a SRM realmente se constitua como um espaço de contribuição significativa para o processo de Inclusão.

Assim, o objetivo deste artigo é discutir o papel das SRM no ensino de ciências, de maneira a promover a inclusão educacional como uma prática possível nas escolas.

\section{A Sala de Recursos como Espaço de Inclusão Educacional}

A SRM é um programa de atendimento educacional especializado que se consolida no atual cenário educacional como um aporte à proposta de Educação Inclusiva (EI). Com o objetivo de complementar e suplementar o trabalho desenvolvido na classe comum, esse programa foi instituído na rede regular de ensino de forma a promover a inclusão educacional.

De acordo com Anjos (2011), as salas de recursos começaram a ser idealizadas na década de 70, com o intuito de atender as pessoas com deficiência que já frequentavam o ensino regular, mas, oficialmente, essas salas só surgiram em 1980.

Tida como um marco no compromisso de uma 'educação para todos', a Declaração de Salamanca, em 1994, reconhece a necessidade de providenciar educação igualitária para pessoas com necessidades educacionais especiais na rede regular de ensino, desse modo afirmando o conceito de inclusão escolar e social. (FIGUEIRA, 2013)

Com a Lei de Diretrizes e Bases da Educação Nacional 9394/96, há a reafirmação da proposta de educação inclusiva no contexto escolar brasileiro, conforme preconiza a lei no artigo 58

Entende-se por educação especial, para os efeitos desta Lei, a modalidade de educação escolar oferecida preferencialmente na rede regular de ensino, para educandos com deficiência, transtornos globais do desenvolvimento e altas habilidades ou superdotação. (BRASIL, 1996)

Ao estabelecer que a educação de alunos com deficiência deva ser preferencialmente na rede regular de ensino, a lei define a escola como um espaço de inclusão, porém, no parágrafo primeiro do referido artigo, há um reconhecimento das possíveis dificuldades para a escola em efetivar esse processo.

$\S 1$ 10 Haverá, quando necessário, serviços de apoio especializado, na escola regular, para atender às peculiaridades da clientela de educação especial. (BRASIL, 1996)

Em cumprimento à legislação, o serviço de atendimento educacional especializado de SRM assume a tarefa de promover a inclusão. No entanto, essa tarefa não se restringe 
ao programa e ao professor especialista, trata-se de um trabalho conjunto e que demanda participação da escola como um todo, da família e, quando necessário, de acompanhamento clínico.

No estado do Paraná, as SRM são regulamentadas pela Instrução nº 016/2011 SEED/SUED que estabelece:

O trabalho pedagógico a ser desenvolvido na Sala de Recursos Multifuncional - Tipo I, na Educação Básica deverá partir dos interesses, necessidades e dificuldades de aprendizagem específicas de cada aluno, oferecendo subsídios pedagógicos, contribuindo para a aprendizagem dos conteúdos na classe comum e, utilizando-se ainda, de metodologias e estratégias diferenciadas, objetivando o desenvolvimento da autonomia, independência e valorização do aluno. (PARANÁ, 2011, p.05)

De acordo com a Deliberação 02/03, o público-alvo da SRM são alunos com deficiência intelectual e transtornos funcionais específicos que estão inclusos na rede regular de ensino.

No entendimento de Coll, Marchesi e Palacios (2004), a Deficiência Intelectual é caracterizada como limitações sérias em diferentes âmbitos, entre eles, o intelectual e adaptativo funcional.

No trabalho educacional de pessoas com deficiência intelectual, tornam-se importantes e necessários, além dos conhecimentos sobre o processo de ensino e aprendizagem, o conhecimento das concepções da deficiência e a crença nas possibilidades de aprendizagem do aluno, que é o princípio da ação pedagógica e da definição das estratégias pedagógicas a serem empregadas no processo. (LOPES; MARQUEZINE, 2012, p. 491)

$\mathrm{Na}$ fala dos autores, fica explícita a possibilidade de promoção da inclusão educacional dos alunos com deficiência intelectual. Para tanto, são apontados como fatores essenciais: o conhecimento da deficiência e a crença na possibilidade de promover o processo de ensino aprendizagem, por meio de estratégias e práticas pedagógicas diferenciadas. SRM.

Alunos com Transtornos Funcionais Específicos são considerados público-alvo da

Referindo-se à funcionalidade específica do sujeito, sem o comprometimento intelectual do mesmo. Diz respeito a um grupo heterogêneo de alterações manifestadas por dificuldades significativas: na aquisição e uso da audição, da fala, leitura, escrita, raciocínio ou habilidades matemáticas, na atenção e concentração. (PARANÁ, 2011, p. 2)

Conforme os dados da APA (2014), os Transtornos Funcionais Específicos compreendem a dificuldade em aprender as habilidades acadêmicas básicas como: a leitura de palavras de forma exata e fluente, a compreensão da leitura, a escrita, cálculos matemáticos e interpretação e resolução de situações-problemas.

Há que se ressaltar, também, o surgimento de dificuldades nas demais áreas do conhecimento como em história, ciências e estudos sociais. O diagnóstico do transtorno específico da aprendizagem somente pode ser realizado, após o ingresso do indivíduo na educação formal. (APA, 2014) 
Os alunos com Transtorno do Déficit de Atenção com Hiperatividade (TDAH) são também considerados como público-alvo da Educação Especial. O TDAH é um dos maiores problemas que afetam as crianças, esse transtorno compromete as relações intra e interpessoais da criança. (CONDEMARÍN; GOROSTEGUI; MILICIC, 2006)

De acordo com o manual diagnóstico e estatístico de transtornos mentais (APA, 2014), entre as características diagnósticas que definem o TDAH destaca-se o padrão persistente de desatenção e/ou hiperatividade-impulsividade que interfere no funcionamento ou no desenvolvimento.

Uma vez constatados os diagnósticos dos alunos e reconhecidas as suas necessidades e potencialidades, cabe à escola promover a inserção do aluno no processo de ensino e aprendizagem, por meio da instituição de programas que de fato atendam essa demanda.

A SRM é conduzida por professor especialista em educação especial que atua em conjunto com a equipe pedagógica e professores do ensino regular. Juntos, professores das salas de recursos multifuncionais, professores da classe comum e equipe pedagógica devem definir estratégias pedagógicas que favoreçam o acesso dos alunos inclusos ao currículo e ao grupo, promovendo a inclusão. (ANJOS, 2011)

Para se efetivar a inclusão educacional da forma idealizada, há um processo de construção que envolve a participação do coletivo escolar na promoção de estratégias que corroborem com o ideal dos direitos humanos.

Partindo da concepção apresentada pela autora é possível considerar como função do professor de SRM trabalhar em conjunto com os demais profissionais, de modo a promover a articulação e organização do trabalho pedagógico.

\section{O ensino de ciências na perspectiva Inclusiva}

Há uma grande preocupação que permeia os profissionais das diferentes áreas do ensino em efetivar o processo de inclusão educacional de modo a cumprir os objetivos na formação dos educandos e não, simplesmente, garantir o acesso de todos à escola. Essa preocupação conduz a uma reflexão sobre quais os objetivos a serem atingidos e como tratar as diferenças.

Conforme Carvalho (2012, p. 53)

O que de imediato constatamos é a composição heterogênea do alunado. São todos diferentes uns dos outros, seja em suas características corporais, comportamentais, seja em suas experiências de vida, nas atitudes, nos seus estilos de aprendizagem, em seus interesses, seja em suas motivações para aprender e para participar.

É importante se ter claro que as diferenças existem e devem ser trabalhadas. Não há como ignorar o fato de que uma sala de aula constitui-se em um espaço heterogêneo, mas que o objetivo de promover o conhecimento não deve ser restrito. Pensar em caminhos que conduzam aos objetivos demanda do respeito às diferenças e organização de estratégias de ensino que contemplem essas diferenças.

Como possível modalidade de organização didática e administrativa do sistema escolar, a E I tem se instituído como desafio para estudantes, pais, professores, administradores, legisladores, pesquisadores e sociedade em geral. Fato este que é deflagrado devido às controversas interpretações de seu significado e de sua clientela. (BENITE, A.; BENITE, C.; VILELARIBEIRO, 2015, p. 85) 
Os referidos autores apontam para o fato de que, ao considerar o período marcado pela exclusão no sistema educacional, a educação inclusiva ainda se constitui como um desafio à sociedade de um modo geral. A referida sociedade, por vezes, visando justificar o atraso na adoção de medidas e propostas inclusivas, alegam razões equivocadas como: os obstáculos à acessibilidade física, número excessivo de alunos e falta de recursos, bem como a falta de preparo dos profissionais para atenderem a demanda de alunos.

Quanto à educação científica, Pozo e Crespo apontam para as novas metas que superam a ideia compartilhada por muitos professores de que a educação científica consiste na transmissão do saber científico alienado às necessidades sociais. Percebemse características dessa mudança nos objetivos do ensino, nos conteúdos e métodos utilizados (POZO; CRESPO, 2009)

Krasilchik e Marandino (2007) destacam a importância do domínio científico e tecnológico como garantia de melhoria na qualidade de vida, bem como a importância da socialização desse conhecimento. Nessa perspectiva, o ensino de ciências tem por objetivo a formação do cidadão cientificamente alfabetizado que ultrapassa os limites do conhecimento de conceitos e métodos, mas capacita para utilização desses conceitos nos desafios do cotidiano e na solução de problemas sociais.

Ao aproximar o conhecimento científico da vida do educando e da sociedade, fica ainda mais evidente a característica inclusiva do ensino de ciências, cuja função é contribuir para a socialização do indivíduo, por meio do conhecimento de sua própria realidade e a aquisição de conceitos que subsidiem a melhoria da qualidade de sua vida.

$\mathrm{O}$ ensino de ciências quando direcionado à realidade e ao cotidiano do aluno tem um grande potencial inclusivo - levar o aluno a compreender a sua própria realidade e propiciar-Ihe condições para a tomada de decisões em seu meio, independente de suas condições sociais, físicas e mentais - é um importante passo para a inclusão educacional que se almeja.

Benite, A.; Benite, C.; Vilela-Ribeiro (2015) chamam a atenção para as dificuldades impostas pela complexidade da linguagem científica, o que nos leva a refletir sobre a importância de adequar os conteúdos e favorecer o acesso do aluno ao conhecimento.

Os autores seguem destacando como problemas de aprendizagem de ciências, o excesso de definições e a sua complexidade apresentadas pelos livros, bem como o caráter imutável e supremo do conhecimento científico. (BENITE, A.; BENITE, C.; VILELA-RIBEIRO, 2015)

Nesse sentido, é importante considerar que a adequação de recursos e estratégias para o ensino de ciências numa perspectiva inclusiva é uma prática essencial para efetivar a inclusão educacional e assegurar a aprendizagem dos conceitos necessários para o indivíduo, como se destaca nesse estudo, no qual foram adotados os procedimentos descritos a seguir:

\section{Procedimentos Metodológicos}

Esta pesquisa foi realizada em uma escola da rede estadual de ensino do município de Ponta Grossa, no Paraná. A escola possui quatrocentos e cinquenta (450) alunos nas séries finais do ensino fundamental. Conta com trinta e três (33) professores, sendo três (03) da disciplina de ciências; destes, dois possuem carga horária de quarenta (40) horas e um com vinte (20) horas aulas semanais. Sua equipe pedagógica é composta por três (03) pedagogos, sendo dois (02) no período matutino e um (01) no período vespertino. 
Atualmente, a escola conta com duas SRM, uma no período matutino e outra no vespertino, as quais atendem vinte e sete (27) alunos que apresentam diferentes diagnósticos clínicos, entre eles: a Deficiência Intelectual e Transtornos Funcionais Específicos como distúrbios de aprendizagem na leitura e escrita e em cálculos matemáticos. Também há um significativo número de alunos com Transtorno do Déficit de Atenção com Hiperatividade, apresentando, também, dificuldades acentuadas de aprendizagem.

A primeira SRM foi implementada na instituição pesquisada pela Secretaria do Estado da Educação, no ano de 2005, no turno da manhã. Em 2007, após avaliação pedagógica no contexto escolar e complementar dos alunos com indicativos de distúrbios de aprendizagem, foi solicitada pela escola a abertura de nova turma, sendo ampliado 0 atendimento contemplando também o turno da tarde.

O programa SRM funciona em uma sala específica, preparada com recursos tecnológicos e materiais pedagógicos complementares como: jogos e brinquedos pedagógicos para auxiliar os alunos e atender suas necessidades.

Participaram do estudo, os três (03) professores da disciplina de ciências das séries finais do Ensino Fundamental, os quais para garantir o anonimato serão identificados P1, P2 e P3; um (01) professor especialista em educação especial que atende no programa de SRM (identificado como PSRM) e um (01) Pedagogo membro da equipe pedagógica.

A coleta de dados se deu por meio de entrevista individual semiestruturada, sendo que o protocolo de entrevista versou sobre as seguintes questões:

- Quais os desafios que os professores e alunos enfrentam no ensino de ciências?

- Quais as suas concepções sobre inclusão educacional?

- Como avaliam a inclusão no atual cenário educacional e no seu contexto escolar?

- Você já atendeu alunos de inclusão?

- Se sim, quais as dificuldades que encontrou para trabalhar com esses alunos?

Direcionado ao ensino de ciências e em relação aos alunos, público-alvo da educação especial, os participantes foram questionados:

- Você acredita que o ensino de ciências possa assumir a característica inclusiva?

- Se sim, de que forma o ensino de ciências pode contribuir para a inclusão de um aluno público-alvo da educação especial?

Para os professores da classe comum também foram acrescidos os questionamentos:

- O que é o programa de atendimento educacional especializado de SRM?

- Como funciona?

- Há um trabalho de forma integrada com o professor especialista da SRM?

- Se sim, de que forma esse trabalho ocorre?

A análise dos dados se deu após leitura e releitura dos dados, os quais foram separados por unidades de significados e, na sequência, foram categorizados observando-se as concordâncias e discordâncias. 


\section{Análise e discussão dos Resultados}

Dos dados coletados nas entrevistas, emergiram três categorias de análise que são apresentadas na sequência, sendo elas: os desafios da inclusão educacional no contexto escolar; o ensino de ciências numa perspectiva inclusiva: uma necessidade; Sala de Recursos Multifuncional: uma possibilidade de inclusão. Os resultados traduzem os posicionamentos dos participantes do estudo quanto à prática educacional inclusiva desenvolvida na instituição e à possibilidade de promover a inclusão educacional dos alunos público-alvo da educação especial por meio do ensino de ciências.

\section{Os desafios da inclusão educacional no contexto escolar}

Apesar de já configurar-se como uma realidade no espaço escolar, a inclusão educacional ainda desperta uma preocupação latente no meio, principalmente no discurso dos educadores que destacam, entre as dificuldades, a falta de formação e preparo para trabalhar com os alunos com necessidades educacionais especiais. Um aspecto marcante encontrado na pesquisa é, por vezes, a falta de conhecimento da deficiência do aluno.

A professora P1 apresenta essa questão na sua fala:

Eu já trabalhei em escola que eu cheguei em sala de aula e nem sabia que a menina tinha problema, porque ninguém me avisou! Ninguém me falou! Não chamaram os professores pra dizer: - Olha, essa menina tem esse tipo de deficiência, ela vai ter dificuldade nisso e nisso. (P1)

O relato da docente evidencia a sua preocupação com a falta de informação em relação às dificuldades dos alunos, na maioria das escolas em que ela já trabalhou, além da falta de entrosamento entre o professor especialista e os demais, o que acaba por dificultar, ainda mais, o trabalho do docente sem formação específica para trabalhar com estes alunos. Rossetto (2015) defende a importância de o professor especialista trabalhar como articulador da organização necessária para a escolarização de seus alunos.

Carvalho (2012) acrescenta que a heterogeneidade dos alunos, em uma sala de aula, demanda de o professor traçar estratégias condizentes e que contemplem essas diferenças. No entanto, há que se reconhecer a necessidade de programas de formação do profissional que contemplem essas questões, tanto na formação inicial como programas de formação continuada.

A necessidade de formação para trabalhar com alunos de inclusão aparece quando os professores foram questionados sobre os desafios enfrentados na inclusão de alunos com deficiência. Os professores do ensino regular informantes destacam a falta de formação específica, de conhecimento sobre as deficiências e as formas de trabalho que possibilitem a inserção do aluno e o aprendizado, o que pode ser constatado na fala de P2: "Uma grande dificuldade que tenho é a falta de formação. Na época da minha graduação não se falava em inclusão, não tive nenhuma disciplina que abordasse o assunto."

Também há o relato da carência de programas de formação continuada que contemplem as necessidades de trabalho com os alunos de inclusão. Na fala da informante da equipe pedagógica em que a Pedagoga destaca:

Há uma carência muito grande de programas de formação continuada que contemplem a inclusão educacional, falta tempo destinado ao conhecimento das deficiências e estratégias de ensino direcionadas ao aluno com deficiência. Talvez até mesmo autonomia da escola para 
organizar os momentos de estudos como semana pedagógica e formação continuada de acordo com as próprias necessidades da escola.

A falta de autonomia das escolas em relação à formação oferecida pela Secretaria de Estado da Educação, na semana pedagógica, é destacada como um problema, uma vez que o conteúdo programático, muitas vezes, não contempla as reais necessidades e demandas da escola e a formação para trabalhar com esses alunos.

Outro aspecto destacado pelos professores da classe comum é a falta de participação e comprometimento da família, tanto no acompanhamento do desenvolvimento das atividades da classe comum, quanto nos programas de atendimento educacional especializado. De acordo com a professora da sala de recursos multifuncionais há uma dificuldade muito grande em conscientizar sobre a importância do atendimento educacional especializado. Ela relata: "Minha principal dificuldade é fazer o aluno perceber a necessidade do atendimento, e de conseguir que a família assegure a frequência do aluno no programa". (PSRM)

Para a equipe pedagógica há uma dificuldade em conscientizar os responsáveis sobre a importância do atendimento, pois segundo a pedagoga, "É muito difícil conseguir até mesmo a presença de muitos pais na escola para tratarem das dificuldades dos filhos, muitos alegam não conseguirem assegurar a frequência do filho no programa".(Pedagoga)

$\mathrm{Na}$ fala, é possível identificar a preocupação com a frequência dos alunos no programa, assim como a importância do papel da família no processo ensinoaprendizagem de modo a garantir a inclusão educacional. Diante desse apontamento, é importante que a escola trabalhe junto à família e que transmita a importância do programa, que não se refere simplesmente a um reforço escolar como defendem Lopes e Marquezine (2012), mas um desafio, um mecanismo de superação e desenvolvimento.

\section{O ensino de ciências numa perspectiva inclusiva: uma necessidade}

Há uma grande preocupação por parte dos profissionais da educação em desenvolver o trabalho de forma a contemplar as necessidades decorrentes da proposta de educação inclusiva, bem como superar os desafios impostos no cotidiano escolar.

$\mathrm{Na}$ pesquisa, quando questionados sobre a possibilidade do ensino de ciências assumir uma característica inclusiva, ou seja, que possa contribuir para a inserção educacional de alunos público-alvo da educação especial, os professores destacam a possibilidade de utilizar-se de conteúdos próximos do cotidiano dos alunos que possibilitem a experimentação e favoreçam a aprendizagem. Conforme se observa nas falas de P1: "Sim, quando você trabalha com as habilidades necessárias para a vida do ser humano. Numa aula experimental, com experiências, há uma maior possibilidade de incluir os alunos, fazendo com que ele possa participar".

Para o PSRM: "Os conteúdos da área favorecem a inclusão do aluno, como o conhecimento e preservação do meio ambiente, questões relacionadas ao conhecimento do próprio corpo, saúde, entre outros".

Diante dos resultados, percebe-se existir consonância com os estudos de Pozo e Crespo (2009) que argumentam que, hoje, muitos professores já superaram a ideia de que a educação científica consiste na transmissão do saber científico alienado às necessidades sociais, uma vez que há uma preocupação desses professores com os conteúdos e sua aplicação na vida dos sujeitos. 
Em relação à questão, "os professores acreditam na possibilidade de inclusão por meio do ensino de ciências"? Todos eles entendem que sim, mas que, para isso, seria necessário transpor para a realidade dos alunos, recursos e alternativas diversificadas, fato evidenciado por P2: "Eu acredito que sim, desde que os conteúdos sejam transmitidos de uma forma acessível e que haja a busca de meios diversificados, alternativas. Que seja acessível ao cotidiano dos alunos".

O que vai ao encontro dos argumentos de Krasilchik e Marandino que destacam a importância do domínio científico e tecnológico como garantia de melhoria na qualidade de vida, o que aproxima, ainda mais, o educando do meio em que vive. Assim sendo, quando nos referimos ao aluno com deficiência, tais objetivos não podem ser eliminados, mas sim estabelecidos como mecanismos de inserção social e inclusão educacional.

Apesar de configurar-se como uma realidade cada vez mais evidenciada nas escolas, a inclusão educacional ainda é considerada como um assunto controverso entre os educadores. Buscando identificar a concepção dos professores participantes do estudo sobre a inclusão educacional dos alunos público-alvo da educação especial, os mesmos, ao serem questionados, reconhecem a inclusão como algo presente nas escolas.

Na fala da P2, destaca-se a concepção de inclusão educacional: "Para mim é fazer com que o aluno tenha acesso a tudo que tem direito". O que se repete na fala da P1, que destaca: "É o atendimento igualitário a todos os alunos independente de suas condições, é tentar dar o suporte necessário para que a aprendizagem realmente ocorra".

Analisando os conceitos apresentados pelas professoras, é possível observar que há uma compreensão dos aspectos legais da inclusão e que esse já se constitui como um paradigma no meio escolar. No entanto, é importante que ao se referir à inclusão educacional, esteja esse conceito atrelado à efetivação da aprendizagem e aos objetivos comuns do ensino. Assim como Carvalho (2012), os professores da instituição reconhecem a diversidade no contexto em que atuam e isso faz com que, consequentemente, seja constatada a necessidade do atendimento a essa diversidade.

Para a pedagoga participante do estudo,

Em alguns momentos, na semana pedagógica e formação em ação, são apresentados conteúdos referentes à educação inclusiva, onde são apresentados aspectos teóricos e legais, no entanto, esses não atendem a demanda prática de formação dos profissionais para atuarem com os alunos.

É imprescindível que a formação dos profissionais esteja pautada na prática coletiva em que, juntos, os profissionais possam trocar experiências de modo a contribuir para a prática pedagógica, assim como afirma Anjos (2011), é importante que juntos, professor especialista, professores da classe comum e equipe pedagógica busquem estratégias e recursos de promoção à Inclusão.

Outro fator que emergiu dos dados são as dificuldades no trabalho com os conteúdos da área de ciências, pois a PSRM não possui formação na área de ciências. Ela acrescenta:

Para o professor de Sala de Recursos é difícil trabalhar os conteúdos específicos da área, eu sou pedagoga e acredito que meu conhecimento não seja suficiente! É difícil desenvolver trabalhos práticos, experiências, atividades que possam auxiliar na compreensão dos alunos. (PSRM) 
A fala da PSRM traduz exatamente as dificuldades relatadas nos estudos de Ribeiro e Benite (2015), os quais chamam a atenção sobre a complexidade da linguagem científica e a dificuldade em transpor para os alunos os conteúdos científicos.

Nesse sentido, acredita-se na importância de um trabalho integrado entre os profissionais, que haja a troca de experiências, quando o professor de ciências pode apresentar os conhecimentos necessários da área e o professor do programa enumerar as possibilidades de atuação, considerando as necessidades e potencialidades do aluno. Há que se ressaltar que a oferta de programas de atendimento educacional especializado como a SRM e o trabalho apenas no programa, por si só, não garantem a inclusão, mas sim se constituem em ações que devem ser assumidas pelo coletivo escolar.

\section{Sala de Recursos Multifuncional: uma possibilidade de inclusão}

Apesar do programa de atendimento educacional especializado ocupar cada vez mais espaço nas escolas regulares, ainda muitos professores da classe comum desconhecem o programa. Segundo a P3, quando questionada sobre o programa: "Sei que é um programa de atendimento que busca maneiras que facilitem a aprendizagem de modo a inseri-lo na escola".

P2 acrescenta; "é o atendimento para as dificuldades do aluno, onde são buscadas maneiras que facilitem a aprendizagem".

Ainda é possível constatar que há certo distanciamento entre o programa e os professores do ensino regular, o que dificulta o trabalho.

$\mathrm{Na}$ fala dos professores entrevistados, são evidenciadas diversas dificuldades enfrentadas pelos professores da classe comum, da sala de recursos e equipe pedagógica em realizar um trabalho de organização e estabelecimento de estratégias, onde juntos possam promover um trabalho integrado de inclusão.

Embora relatem dificuldades na organização de práticas e estratégias, os professores reconhecem a importância da definição de estratégias pedagógicas que possibilitem a inclusão, assim como Anjos (2011), em seus estudos, defende a importância da busca de estratégias pedagógicas que favoreçam o acesso dos alunos inclusos e que os professores que atuam na sala de recursos e os professores do ensino regular devem atuar juntos, definir juntos estratégias pedagógicas que possibilitem a inclusão.

Para P1, a falta de tempo e disponibilidade de horários, ou mesmo a incompatibilidade de horários, impossibilita um trabalho integrado junto ao professor da Sala de Recursos.

Os momentos como a hora atividade não suprem as necessidades de contato com os professores, não há como organizar os horários, pois os professores dos alunos atendidos geralmente estão em turno contrário e não se encontram na escola. (PSRM)

Apesar das dificuldades enfrentadas pelos professores, a pesquisa aponta que o atendimento disponibilizado aos alunos no programa de SRM auxilia significativamente no processo de aprendizagem. Conforme destaca P2, "O atendimento auxilia no processo de aprendizagem por meio do reforço e trabalho diversificado".

$\mathrm{Na}$ fala da professora, é possível constatar que o objetivo do programa descrito na Deliberação 02/03 de complementar e suplementar o trabalho realizado em sala de aula é atingido, uma vez que os conteúdos são trabalhados de forma diversificada e acessível. 
Isso reforça o que Lopes e Marquezine (2012) quando afirmam que os objetivos da SRM vão além do reforço dos conteúdos.

O programa de atendimento educacional especializado surge como um mecanismo de auxílio aos educadores ao proporcionar suporte que tem por objetivo complementar e suplementar o trabalho realizado na classe comum do ensino regular.

\section{Considerações Finais}

É fato que a Inclusão Educacional é, nos dias de hoje, uma realidade cada vez mais evidente no meio escolar. A implementação de programas de atendimento educacional especializado surge como um recurso para a inserção do aluno no processo ensino-aprendizagem.

Como os resultados da pesquisa apontam, apesar das dificuldades enfrentadas como a falta de formação, bem como de tempo e momentos para que juntos, professores especialistas e professores da classe comum do ensino regular possam organizar 0 trabalho, os professores da instituição reconhecem a importância das atividades de reforço e o trabalho diversificado realizado no programa como um auxílio no processo de aprendizagem.

Partindo do pressuposto que o ensino de ciências apresenta características essenciais para a promoção da inclusão, a pesquisa traz nos relatos dos informantes essa possibilidade atrelada a fatores essenciais como a adoção de métodos e estratégias diversificadas que atendam às necessidades educacionais especiais dos alunos.

O que a pesquisa apresenta é a necessidade de se promover a inclusão como uma prática coletiva, uma vez que os resultados da pesquisa ressaltam que essa prática ainda não é efetiva no contexto escolar. Por meio da prática pedagógica coletiva deverão ser somados o conhecimento científico específico do professor do ensino regular e o conhecimento acerca das deficiências e estratégias de ensino que possam otimizar o trabalho com os alunos, de modo a desenvolver suas potencialidades, apesar das suas dificuldades.

Quando no discurso sobre a formação do indivíduo atribui-se a importância de formar o cidadão consciente e participativo que compreende a sua realidade e é capaz de transformá-la, assume-se então, uma importante tarefa que é atribuir esse objetivo à formação que se proporciona na escola sem restrições, de forma igualitária, independente de condições sociais, físicas e mentais. Na pesquisa, foi possível constatar que apesar dos professores e equipe pedagógica relatarem dificuldades, há o compromisso com a formação dos alunos e uma preocupação para que essa formação seja pensada para todos os alunos, o que é visível em diversos relatos que reafirmam a necessidade de promover uma prática realmente inclusiva.

Em suma, a pesquisa aponta para a possibilidade de promover a inclusão educacional por meio do ensino de ciências. No entanto, ainda há um longo caminho a se percorrer para que esse trabalho seja realizado efetivamente na escola.

A identificação de aspectos como a importância do atendimento educacional especializado e a atuação conjunta dos professores do programa, junto aos professores da classe comum e equipe pedagógica, constituem-se em mecanismos de trabalho essenciais para a prática pedagógica inclusiva de modo a promover a inclusão educacional. 


\section{Referências}

ANJOS, I. R. S. dos; O atendimento educacional especializado em Salas de Recursos. Revista Fórum Identidades. Itabaiana: Gepiadde, v. 09, n. 09 p.01-09, jan- jun 2011. Disponível http://200.17.141.110/periodicos/revista_forum_identidades/revistas/ARQ_FORUM_IND_9 /FORUM_V9_01.pdf. Acesso em 23 de fev de 2015.

BENITE, A. M. C.; BENITE, C. R. M.; VILELA RIBEIRO, E. B. Educação inclusiva, ensino de Ciências e linguagem científica: possíveis relações. Revista Educação Especial. v. 28, n. 51, p. 83-92 , jan.-abr. 2015 Santa Maria. Disponível em: http://cascavel.ufsm.br/revistas/ojs-

2.2.2/index.php/educacaoespecial/article/view/7687/pdf>Acesso em: 07 mar. 2015.

BRASIL. Lei de Diretrizes e Bases da Educação Nacional no 9394/96, de 23 de dezembro de 1996. Brasília: Diário Oficial da União, Brasília, DF, 23 dez. 1996.

CARVALHO, R. E. Escola Inclusiva: a reorganização do trabalho pedagógico. 5a ed. Porto Alegre: Mediação, 2012.

FIGUEIRA, E. O que é educação inclusiva. São Paulo: Brasiliense, 2013.

KRASILCHIK, M.; MARANDINO, M. Ensino de ciências e cidadania. $2^{a}$ ed. São Paulo: Moderna, 2007.

LOPES, E.; MARQUEZINE, M. C. Sala de recursos no processo de inclusão do aluno com deficiência intelectual na percepção dos professores. Revista Brasileira de Educação

Especial, Marília, v. 18, n. 3, p. 487-506, jul./set. 2012. Disponível em: <http://www.scielo.br/pdf/rbee/v18n3/a09.pdf >. Acesso em: 10 abr. 2014.

PARANÁ. Deliberação no $02 / 03$ de 02 de junho de 2003. Normas para a educação especial, modalidade da educação básica para alunos com necessidades educacionais especiais, no sistema de ensino do estado Paraná. Curitiba, PR. Disponível em: <http://www.nre.seed.pr.gov.br/maringa/arquivos/File/Educacao_Especial/Deliberacao_02 03.pdf>Acesso em: 02 mai. 2014.

Instrução no $016 / 2011$ de 22 de novembro de 2011. Critérios para o atendimento educacional especializado em Sala de Recursos Multifuncionais Tipo I, na Educação Básica - área da deficiência intelectual, deficiência física neuromotora, transtornos globais do desenvolvimento e transtornos funcionais específicos.

Disponívelem:<http://www.educacao.pr.gov.br/arquivos/File/instrucoes/Instrucao162011.p df>Acesso em 12 mai. 2014.

POZO, J. I. ; CRESPO, M. Á. G. A aprendizagem e o ensino de ciências: do conhecimento cotidiano ao conhecimento científico. 5a ed. Porto Alegre: Artmed, 2009.

ROSSETTO, E. Formação do professor do atendimento educacional especializado: a Educação Especial em questão. Revista Educação Especial v. 28, n. 51, p. 103-116 jan./abr. 2015. Disponível em: <http://cascavel.ufsm.br/revistas/ojs2.2.2/index.php/educacaoespecial/article/view/13367/pdf>. Acesso em: 07 mar. 2015.

Submissão: 09/02/2017

Aceite: 06/09/2017 